\title{
Research Paper \\ Needlestick Injuries and Associated Psychosocial Factors Among the Students of Dental School
}

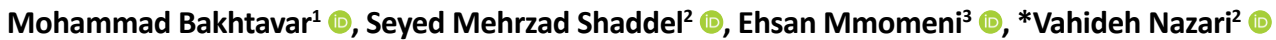

1. Student Research Committee, School of Dentistry, Arak University of Medical Sciences, Arak, Iran.

2. Department of Prosthodontics, School of Dentistry, Kashan University of Medical Sciences, Kashan, Iran.

3. Department of Oral and Maxillofacial Medicine, School of Dentistry, Arak University of Medical Sciences, Arak, Iran

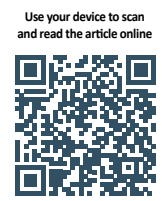

Ciftation: Bakhtavar M, Shaddel SM, Mmomeni E, Nazari V. [Needlestick Injuries and Associated Psychosocial Factors Among the Students of Dental School (Persian)]. Journal of Arak University of Medical Sciences (JAMS). 2021; 24(3):398-411. https://doi.org/10.32598/JAMS.24.3.6209.2

https://doi.org/10.32598/JAMS.24.3.6209.2

Key words:

Needlestick Injuries,

Students, Dental,

Psychology

\section{A B STRACT}

Article Info:

Received: 22 Aug 2020

Accepted: 13 Feb 2021

Available Online: 01 Aug 2021

\begin{abstract}
Background and Aim Needlestick injury (NSJ) is a common occupational health problem among dental healthcare workers, putting them at significant risk for blood-borne infections. This study aimed to investigate occupational exposure to NSJ and the psychological factors associated with it among dentistry students.

Methods \& Materials This descriptive cross-sectional study was carried out on students in the Arak school of dentistry training curriculum in the last three years in 2018. The questionnaires included questions about students' awareness of NSJ conditions, the frequency of vaccinations, and antibody titration tests. The SCL-90 (Symptom checklist-90) questionnaire assessed psychological factors after NSJ in four dimensions of anxiety, phobia, self-morbidity, and depression. Data analysis was performed using descriptive statistical methods and a chi-square test.

Ethical Considerations The study was approved by the Arak University of Medical Sciences (Code: IR.ARAKMU.REC.1397.269)

Results Of the eighty students surveyed, 59 students had experienced NSJ at least once. However, only $25.4 \%$ of students had reported the NSJ occurrence. The highest incidence rate of NSJ was reported in the endodontics section. In addition, $80 \%$ of students had received hepatitis B vaccinations. Based on the SCL-90 test, the anxiety dimension was more affected by NSJ than the other dimensions.

Conclusion Despite the high prevalence of NSJ in dental students, the rate of reporting after the accident is very low. Also, due to the lack of attention to vaccination in some students, there is a need for more infection control training. Based on the SCL-90 test, the occurrence of NS is effective in causing psychological problems.
\end{abstract}

\section{Extended Abstract}

\section{Introduction}

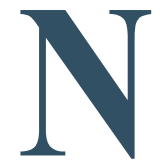

eedlestick is one of the most common occupational hazards that threaten dental center staff [1-3]. The most common way of transmitting pathogens to dental personnel is through subcutaneous injuries [4]. These injuries can have significant health and psychological consequences $[5,6]$ and impose many costs on individuals and society [7]. Various studies have shown that almost all dental staff is exposed to the NS $[8,9]$. The prevalence of NS injuries has been reported in the high educational center [10].

\section{* Corresponding Author:}

Vahideh Nazari, DDS, MSc.

Address: Department of Prosthodontics, School of Dentistry, Kashan University of Medical Sciences, Kashan, Iran

Tel: +98 (863) 3136055

E-mail: nazari.vahideh@yahoo.com 
By determining the prevalence of NSI and understanding the factors influencing its occurrence, designing standard educational protocols to prevent NS, and providing the necessary psychological counseling, NS's risks and psychological effects can be reduced. Therefore, the present study was conducted to investigate the occupational exposure to NSJ and psychosocial factors associated with it among students of Arak Dental School.

\section{Materials and Methods}

The present cross-sectional-descriptive study was performed on dental students of Arak University of Medical Sciences in 2018. The instrument used in the study was the checklist and SCL-90 questionnaire.

Table 1. The level of knowledge and education of students and laboratory tests and vaccination performed by them

\begin{tabular}{|c|c|c|}
\hline Variable & Answer & No. (\%) \\
\hline \multirow{2}{*}{ Students trained in the ability to deal with NS } & Yes & $39(48.75)$ \\
\hline & No & $41(51.25)$ \\
\hline \multirow{3}{*}{$\begin{array}{c}\text { Creating the ability to deal with NS through } \\
\text { training }\end{array}$} & Yes & $15(18.8)$ \\
\hline & No & $27(46.2)$ \\
\hline & somewhat & $28(35)$ \\
\hline \multirow{2}{*}{ Hepatitis B vaccination in students } & Yes & $64(80)$ \\
\hline & No & $16(20)$ \\
\hline \multirow{4}{*}{$\begin{array}{l}\text { Frequency of students based on the number } \\
\text { of doses of vaccine injected }\end{array}$} & once & $15(24.2)$ \\
\hline & Twice & 11(17.7) \\
\hline & three times & $34(54.8)$ \\
\hline & More than three times & $2(3.2)$ \\
\hline \multirow{2}{*}{ Antibody titer testing } & Yes & $45(56.2)$ \\
\hline & No & $35(43.8)$ \\
\hline \multirow{3}{*}{ Rapid test of the patient } & Yes & $8(10)$ \\
\hline & No & $65(81.2)$ \\
\hline & Did not answer & $7(8.8)$ \\
\hline \multirow{3}{*}{ HIV, HBS Ag and HCV Ab tests on the patient } & Yes & $14(17.5)$ \\
\hline & No & $59(73.8)$ \\
\hline & Did not answer & $7(8.85)$ \\
\hline \multirow{3}{*}{ HIV, HBS Ag and HCV Ab tests on students } & Yes & $17(21.3)$ \\
\hline & No & $56(70)$ \\
\hline & Did not answer & $8(8.8)$ \\
\hline \multirow{3}{*}{ Awareness of diseases transmitted by NS } & Yes & 70(87.5) \\
\hline & No & $9(11.3)$ \\
\hline & Did not answer & $1(1.3)$ \\
\hline
\end{tabular}


Table 2. SCL-90 test results

\begin{tabular}{|c|c|c|c|c|c|}
\hline Variable & & & No. $(9$ & & Total \\
\hline Asymptomatic & $14(24.6)$ & $26(45.6)$ & $26(45.6)$ & $35(1.4)$ & $0(0)$ \\
\hline Slight & $32(56.1)$ & $23(40.4)$ & $26(45.6)$ & 19(33.3) & $44(77.2)$ \\
\hline Medium & $7(12.3)$ & $8(14)$ & $5(8.8)$ & $3(5.3)$ & $11(19.2)$ \\
\hline Severe & $4(7)$ & $0(0)$ & $\mathrm{O}(0)$ & $0(0)$ & $2(3.5)$ \\
\hline
\end{tabular}

The first part of the checklist was related to demographic information. The next part of the checklist was related to NS questions, including NS report, student awareness, and conditions of NS occurrence, post-NS tests, and hepatitis B vaccination. SCL 90 test was used to assess mental health $[11,12]$. Four psychological factors of anxiety, fear, selfmorbidity, and depression were examined [11].

The test has a 5-point scale of zero, quantitative, partial, high, and severe, with $0,1,2,3,4$ scores, respectively [13, 14]. To evaluate the reliability, thirty students were randomly selected and completed a questionnaire. Cronbach's alpha coefficient was determined [11]. The validity of the questionnaires was examined using reliable sources and the opinions of experienced professors [15].

Descriptive analysis was expressed for quantitative variables with mean and standard deviation and qualitative variables with frequency and percentage. Chi-square test, Fisher's test, and independent t-test were used in inferential statistics.

\section{Results}

Of the 80 students in the study, 42 female and 38 male, 59 reported a history of NSJ. The frequency distribution of NSJ is related to student's academic year and was significantly higher among sixth-year students and less among fifth-year students $(\mathrm{P}<0.05)$. The frequency distribution of NS was not significantly related to the gender of the students $(\mathrm{P}>0.05)$. Out of 59 students who became NS, 15 reported it. The rate was higher among students who had just entered the clinic, but this difference was not statistically significant $(\mathrm{P}>0.05)$. Among students, 41 were aware of the necessary care after NS. However, the level of knowledge was not significantly related to students' academic year $(\mathrm{P}>0.05)$.

Among the various devices that cause NSI in the dental school, endo files had the highest percentage (44.36\%) and frequency, and dental needles $(27.81 \%)$ were in the next order. Also, among the various actions that may cause NS injuries, the highest percentage was reported during end- odontic treatment $(27.89 \%)$ and then while cleaning equipment for sterilization (20.40\%). The laboratory tests and vaccines performed by them are shown in Table 1 .

Regarding mental health, students had the highest score in the anxiety dimension $(1.58 \pm 0.68)$ and the lowest score in the self-morbidity dimension $(1.17 \pm 0.33)$. The mean scores in depression and fear were $1.35 \pm 0.48$ and $1.28 \pm 0.39$, respectively; 44 people had mild psychological symptoms, 11 people had moderate symptoms, and 2 had severe symptoms (Table 2).

\section{Discussion and Conclusion}

Infection control in educational centers is always of particular importance [16]. The high prevalence of NS in the present study indicates the need to prevent NS. The frequency of NS was significantly higher among sixth year students. Sixth-year students were present in most clinical wards, indicating the highest likelihood of NS. The frequency of NS was not significantly related to the sex of students. However, the highest incidence of NS was observed in women, which indicates that women are more sensitive to NS [17]. Regarding training effectiveness in dealing with NS, $46.3 \%$ of students considered this training ineffective. Among the various conditions that cause NS, the highest incidence was while using the tool, and recommended that students be more careful when using the equipment. The most common cause was endo files. In the Shah study, this was reported while cleaning equipment, which is not consistent with the present study [18]. $80 \%$ of the students were vaccinated against hepatitis B. In the study of Asgarian, $86.2 \%$ of the students were vaccinated against hepatitis $\mathrm{B}$ [8]. Because the safest way to protect against hepatitis B is to get vaccinated, students should have their antibody titers checked periodically [19]. SCL-90 test scores after NS were high, even higher than the scores of the same test in the study of Tabrizizadeh, Which shows that the occurrence of NS can play a significant role in the occurrence of psychological problems [14]. In the study of Mehrad, Anxiety was also reported to be associated with NS [5]. 
Due to the high prevalence of NS, there is a need to appropriate training courses and minimize the incidence of psychological damage by increasing awareness and wellorganized educational planning.

\section{Ethical Considerations}

\section{Compliance with ethical guidelines}

The study was approved by the Arak University of Medical Sciences (Code: IR.ARAKMU.REC.1397.269).

\section{Funding}

The study was extracted from the $\mathrm{PhD}$ dissertation of the first author at the Student Research Committee, School of Dentistry, Arak University of Medical Sciences, Arak.

\section{Authors' contributions}

All authors met the standard writing criteria based on the recommendations of the International Committee of Medical Journal Publishers.

\section{Conflicts of interest}

The authors declared no conflict of interest. 
This Page Intentionally Left Blank 


\section{جراحت ناشى از سوزن و عوامل روانى همراه با آن در ميان دانشجويان دثدانيزئشى}

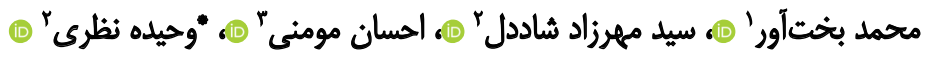

ا. مركز تحقيقات دانشجويى، دانشكاه علوميزشكى اراك، ارإى، ايران.

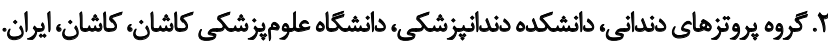

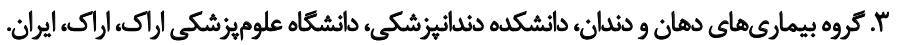

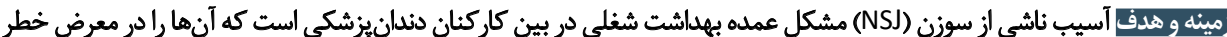

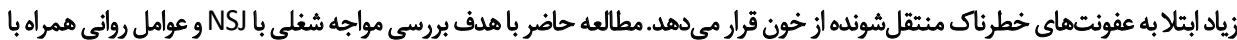

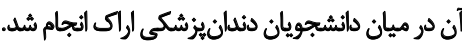

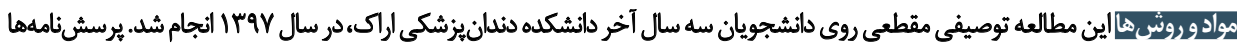

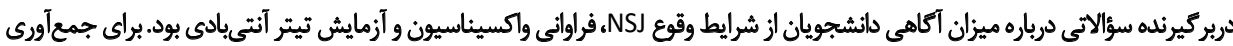

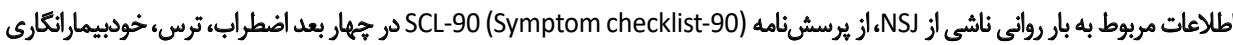

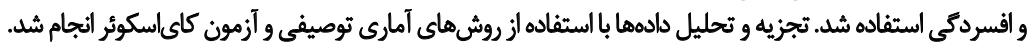

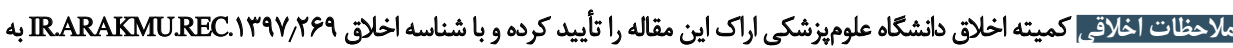
ثبت رسانده است.

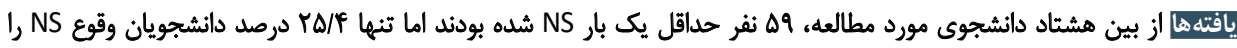

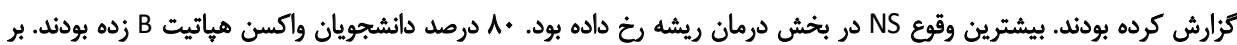

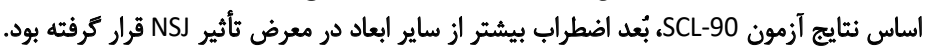

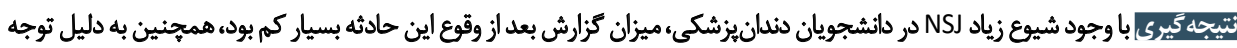

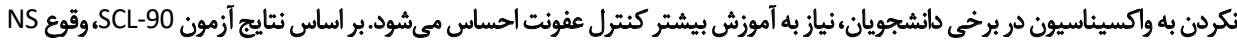
در بروز مشكلات روانى مؤثر است. نيت.

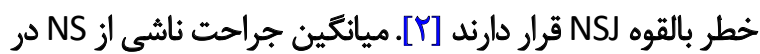

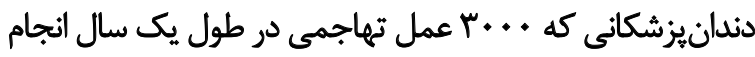

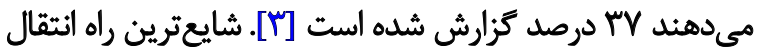

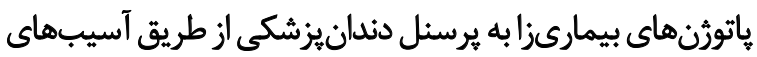

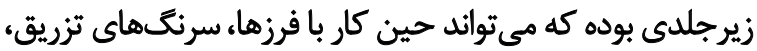

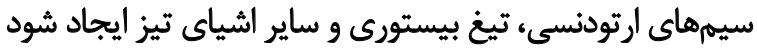

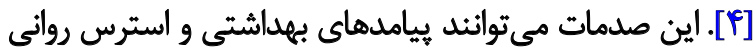

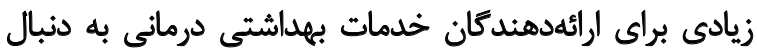

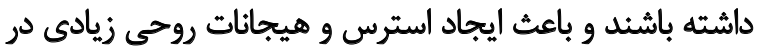

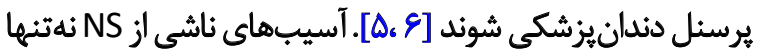

أسيب ناشى از جراحت سوزن يكى از بزركترين و شايعترين

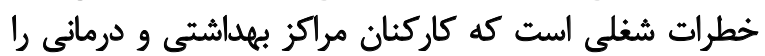

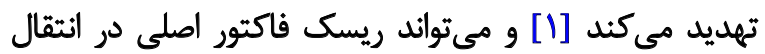

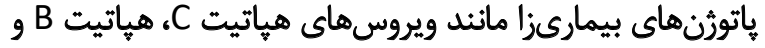
ويروس نقص ايمنى اكتسابي (HIV) عمل كند [TIV] دندانيزشكان همجون ساير حرفههاى يزشكى در معرض

1. Needlestick Injury (NSJ) 


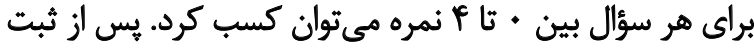

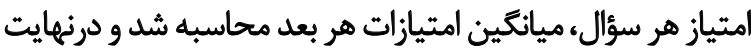

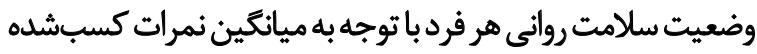
در آن بعد در هجهار طبقه: فاقد اختلال رواني (•- (1)، اختلال رواني

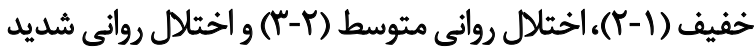

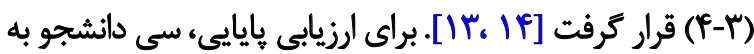

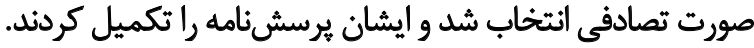

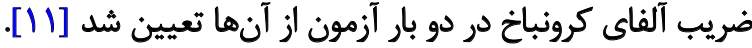

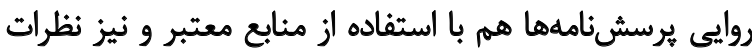

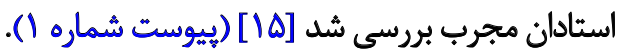
Sادهاي جمع آورى شده وارد برنامه آمارى SPSS كنسخه Y Y شد. آناليز توصيفى براى متغيرهاى كمئ بادي با ميانكين و انحراف معيار

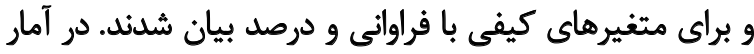

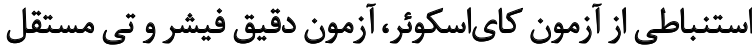
استفاده شد.

يافتهها

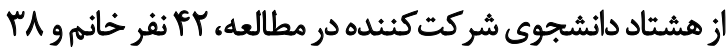

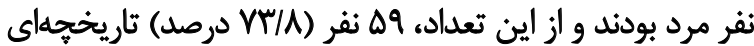

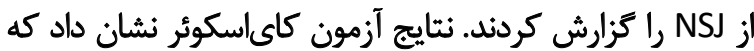

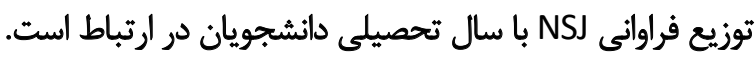
اين توزيع در بين دانشجويان سال شش به به شكل معناداري باري بيشتر

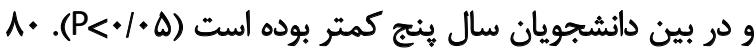

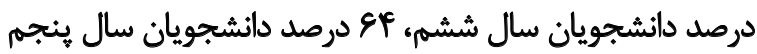

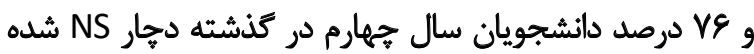

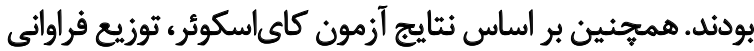

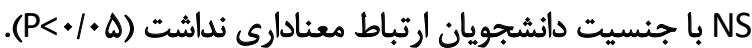

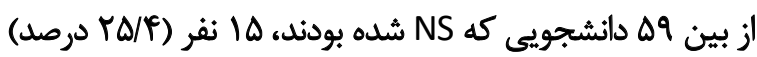

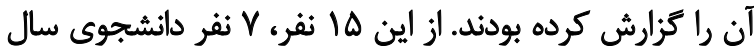

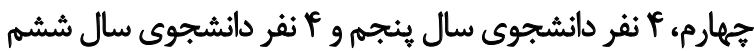

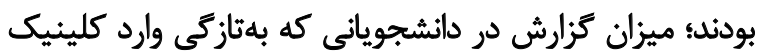

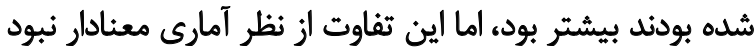

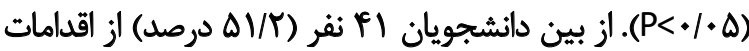

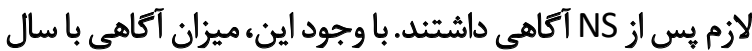

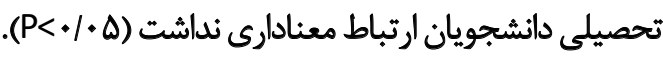
از بين وسايل متفاوتى كه باعث بروز آسيبهاي NS در دري

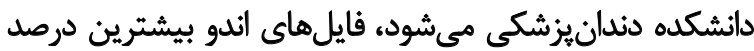

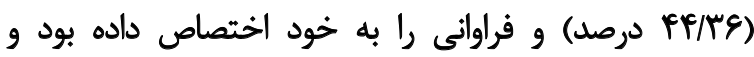

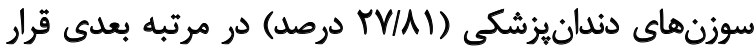

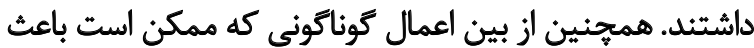

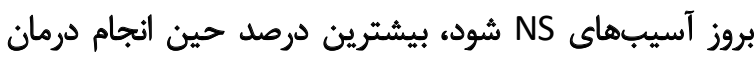

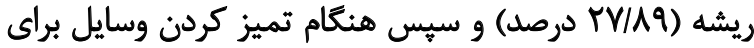

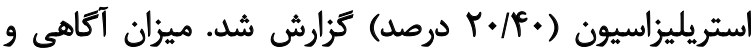

باعث افزايش احتمال بيمارىهاى عفونى مي شود بلكه هزينهاي

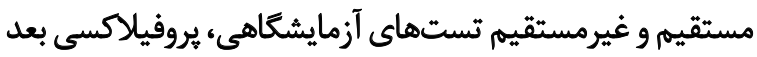

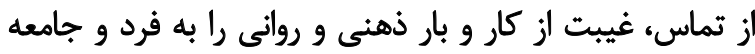

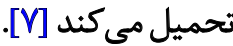
بررسى مطالعات كوناكون نشان داد كه تقريباً تمام كادر درمان

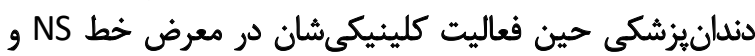

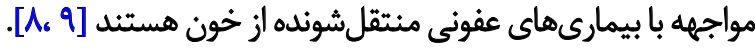

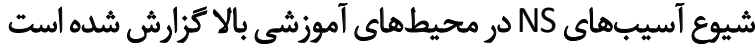
و از اين جهت اهميت زيادى دارد [ـ/1]. با تعيين شيوع صدمات ناشى از NS و و بي بردن به عوامل

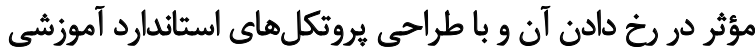

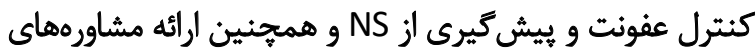

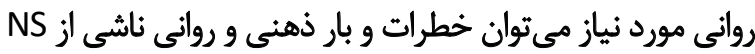

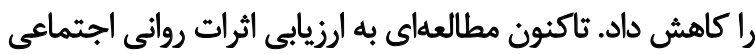

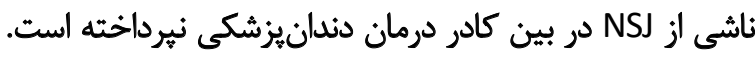

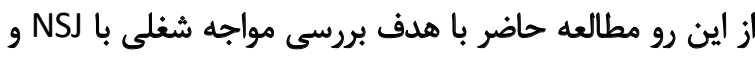

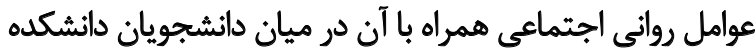

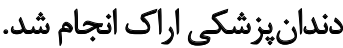

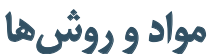

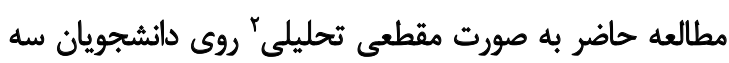

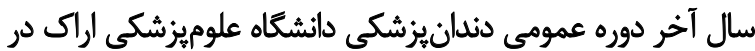

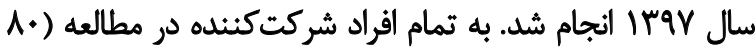

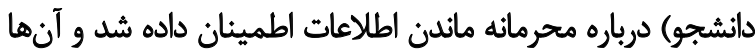

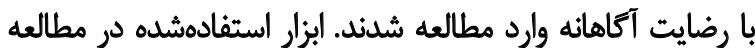

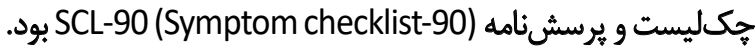
بخش اول سؤالات جكىليست مربوط به إنهات

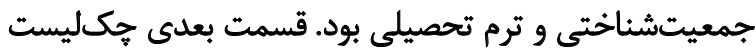

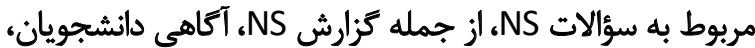

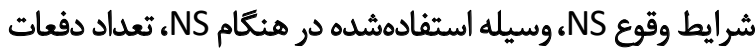

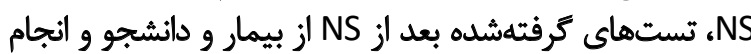

$$
\text { واكسيناسيون هياتيت B در دانشجو بود. }
$$

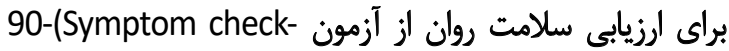
list-90) SCL

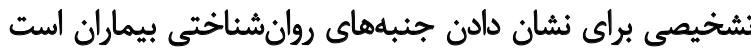

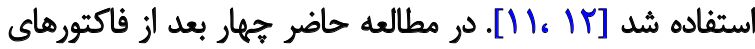

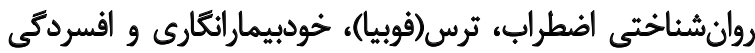

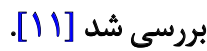

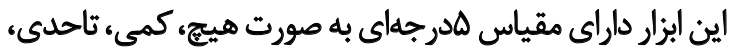

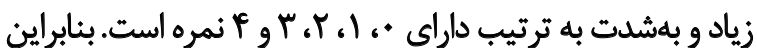

2. Cross sectional-descriptive study 
جدول ا. ميزان آكاهى و آموزش دانشجويان و تستهاى آزمايشكاهى و واكسيئاسينون انجامشده آنها

\begin{tabular}{|c|c|c|}
\hline قراوانى (درصد) & هاسخ & متغيرها \\
\hline $\begin{array}{l}\mathrm{rq}(F N \vee \Delta) \\
F((\Delta) / T \Delta)\end{array}$ & خبلى & دانشجويان آموزش ديده در زميئه توانايى مقابله با NS \\
\hline 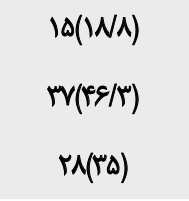 & تا حيلي & ايجاد توانايع مقابله با NS در ائر آهوزش ها \\
\hline $\begin{array}{l}e f(A \cdot) \\
I P(Y *)\end{array}$ & خيلى & واكسيناسيون هياتيت B در دانشجويان \\
\hline $\begin{array}{l}M \Delta(T Y / T) \\
M(I V / Y) \\
M F(\Delta F / A) \\
r(T / T)\end{array}$ & 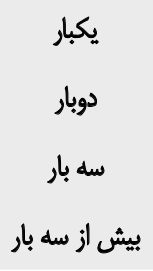 & فراوائى دانشُجويان بر اساس تعداد نُز واكسن تزريقشهـه \\
\hline $\begin{array}{l}r \Delta(\Delta \& / Y) \\
r \Delta(T r / A)\end{array}$ & بلى & انجام آزمايش ثيثر آنتىبادى \\
\hline $\begin{array}{c}A(1 \cdot) \\
\left.\& \Delta(A) / N^{\prime}\right) \\
V(N A)\end{array}$ & بلي & أنجام أزمايش Rapid test از بيمار \\
\hline $\begin{array}{l}I f(I V / \Delta) \\
\Delta q(N / \Lambda) \\
V(N \Lambda)\end{array}$ & خيلى باسيخ نداده & انجام أزمايشهاى HCV Ab , HIV Ab HBS Ag از بيمار \\
\hline $\begin{array}{l}I V\left(Y \backslash / N^{*}\right) \\
\Delta E\left(V^{*}\right) \\
N(N A)\end{array}$ & خيلى خياسن نداده & انجام أزمايش هاى HIV Ab HBS Ag و HCV Ab در دانشجويان \\
\hline $\begin{array}{l}V \cdot(A V / \Delta) \\
9(11 / /) \\
1\left(1 / T^{\Psi}\right)\end{array}$ & خيلي & أكاهى از بيمارى هاى متثقل شده توسط NS \\
\hline
\end{tabular}

19/T/T ( ل دV/T)

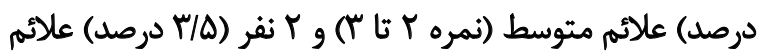

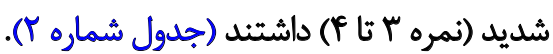

4

كنترل عفونت در مراكز ارائه خدمات آموزشى درمانى هميشه
آموزش دانشجويان و تستهاى آزمايشكاهى و واكسيناسينون انجامشده آنها در جدول شماره إنشان داده شده است. درباره سلامت روان، دانشجويان در بعد اضطراب بيشترين

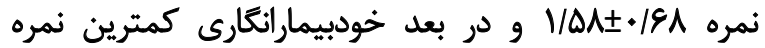

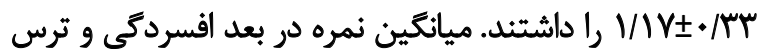

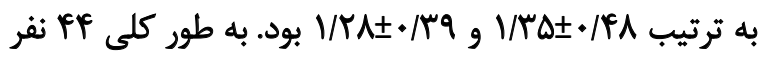




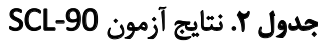

\begin{tabular}{|c|c|c|c|c|c|}
\hline \multicolumn{6}{|c|}{ فراوانى (درصد) } \\
\hline كل & خودبيماراتكارى & ترس & افسردكى & اضطراب & تتايج \\
\hline$\cdot(\cdot)$ & $r \Delta(F / / P)$ & $r g(f \Delta / q)$ & $r E(F \Delta / F)$ & $I F(r f / g)$ & فاقد علاثم \\
\hline $\operatorname{Pr}(W / T)$ & $19(M r / m)$ & $r g(P \Delta / g)$ & $M \mu(\varphi \cdot / \mu)$ & $\operatorname{rr}(\Delta \& / 1)$ & خفيف \\
\hline $11(19 / 4)$ & $r(\Delta / \pi)$ & $\Delta(N A)$ & $A(1 F)$ & $V(1 T / \pi)$ & متوسط \\
\hline$r(r / \Delta)$ & $\cdot(\cdot)$ & $\cdot(*)$ & $+(*)$ & $F(M)$ & شديد \\
\hline
\end{tabular}

(sings

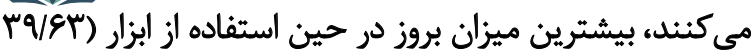

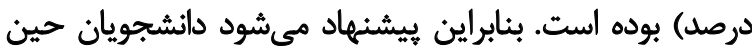

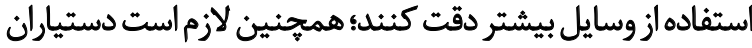

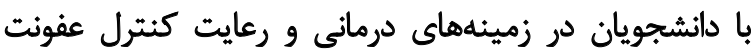

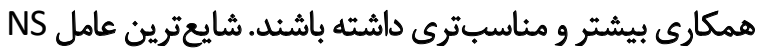

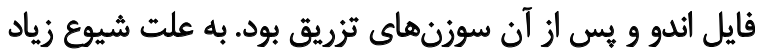

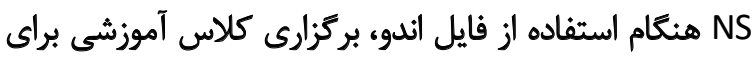

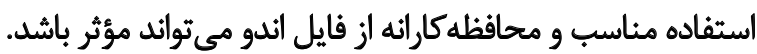

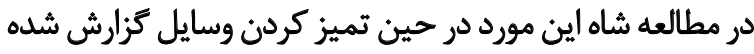

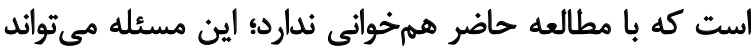

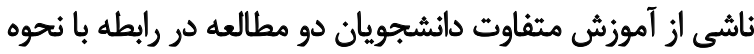

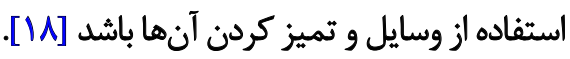
از بين افراد مطالعهشده • A درصد افراد در مقابل هياتيت

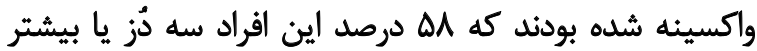

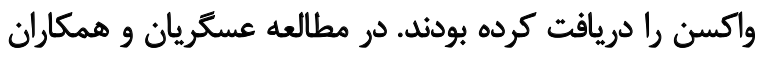

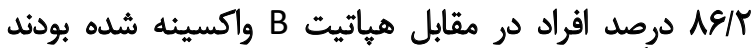

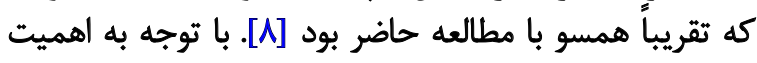

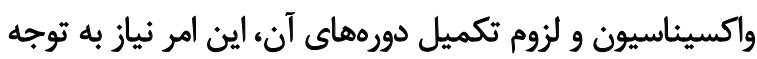

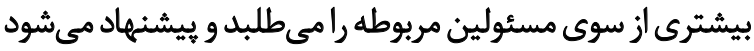

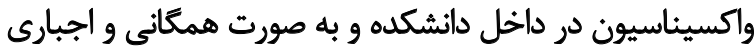

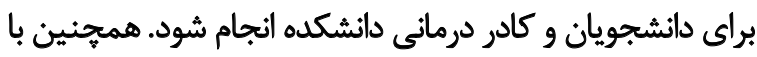

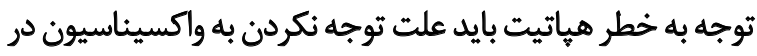
برخى دانشجويان بررسى شود.

از آنجا كه مطمئنترين راه ايمنى در برابر هياتيت

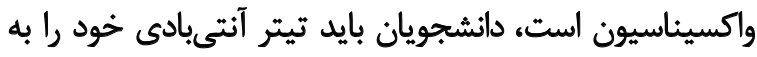

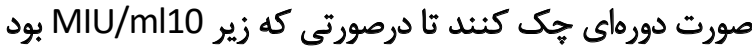

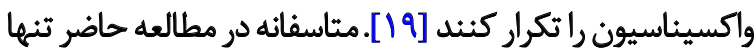

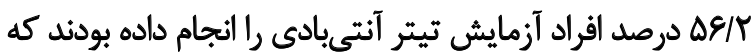

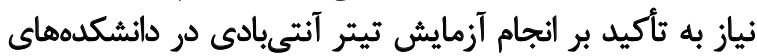

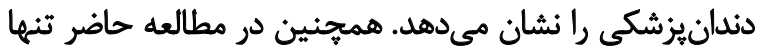

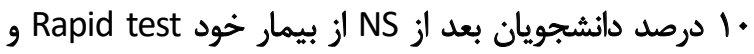

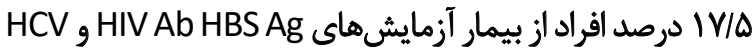

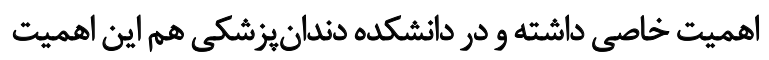

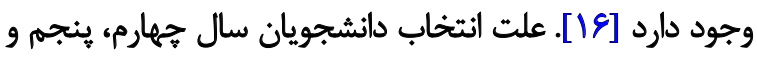

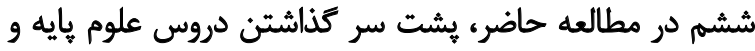

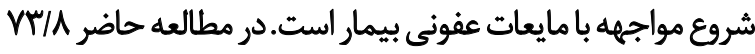

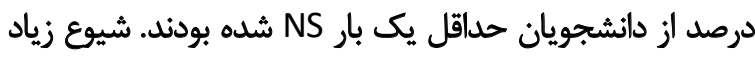

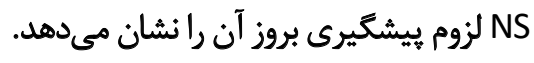

بر اساس نتايج مطالعه حاضر، توزيع فراوانى NS در بين دين

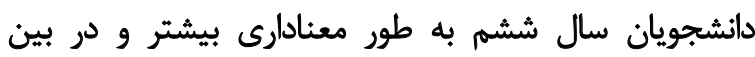

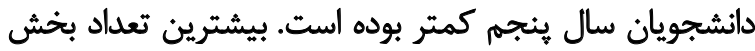

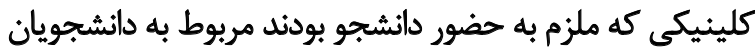

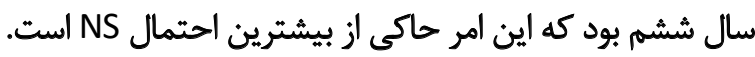

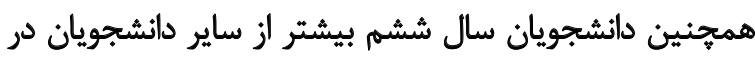
بخش درمان ريشه و جراحى كه ميزان خطر NS NS بيشترى دارندئ داند

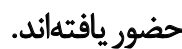

توزيع فراوانى NS با جنسيث دانشجويان ارتباط معنادارى

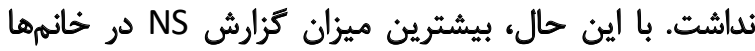

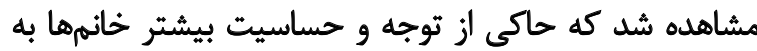

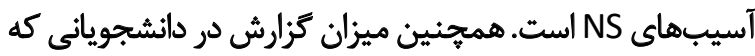

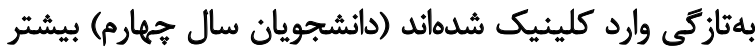

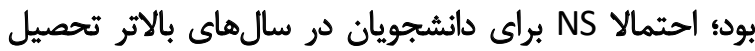

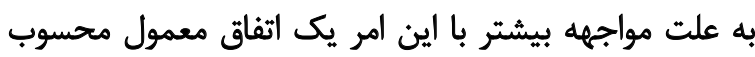

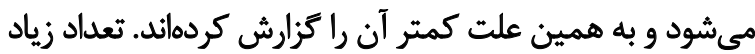

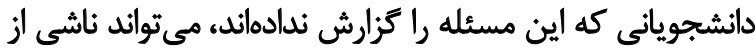

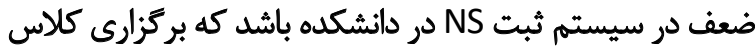

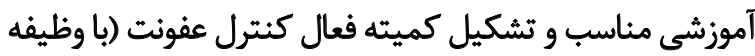

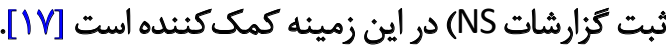
داباره مؤثر بودن اين آموزشها بايد كفت كه در زمينه مقابله

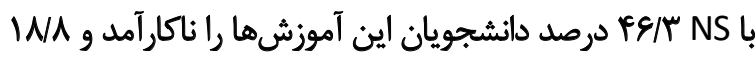

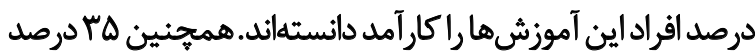

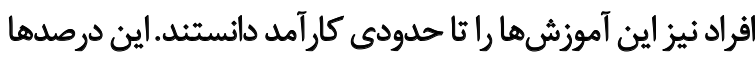

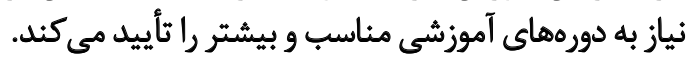
از بين شرايط كوناكونى كه زمينه را براى وقوع NS فراهم 
ندادن NS و راهكارهاى افزايش تزارشدهى بررسى شود. بهتر

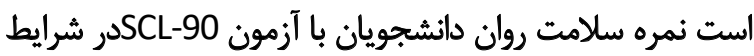
اتفاق نيفتادن NS تعيين شود و مقايسه نتايج آن با مطالعه حاضر

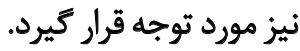
ملاحظات اخلاقيى

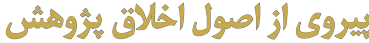

كميته اخلاق دانشكاه علوميزشكى اراك اين مقاله را تأييد

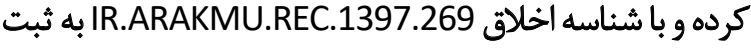
رسانده است.

$$
\text { Nho sols }
$$

اين مقاله از رساله دكترى نويسنده اول در مركز تحقيقات

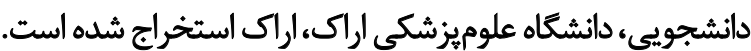

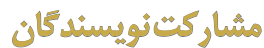

نويسندكان استانداردهاى نوشتارى را بر اساس كميته بين المللى ناشران مجلات يزشكى (ICMJE) رعايت كردانداندان

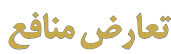

نويسندكان بدينوسيله تصريح مى كنئد كه هيجگونه تضاد منافعى در يُؤهش حاضر وجود ندارد.
را آرفته بودند. T/T Ab

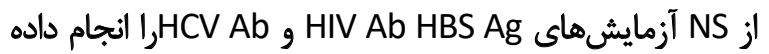
بودند. دانشجويان با افزايش آتاهى از اين تستها مي توانواند انجام آن آنها را افزايش دهند.

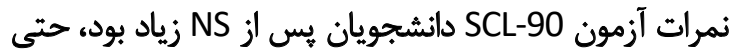

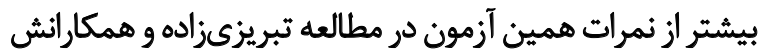

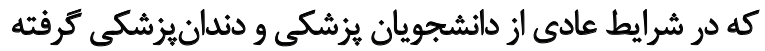

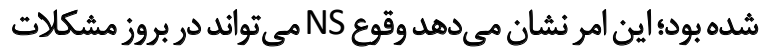

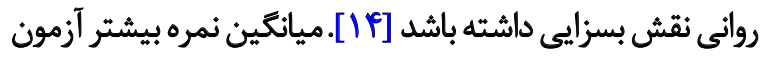

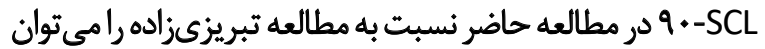

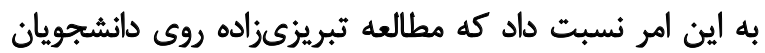

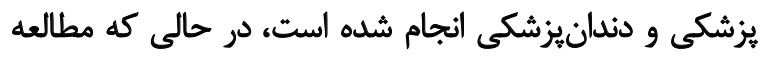

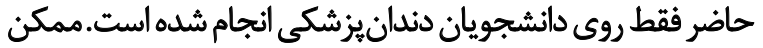

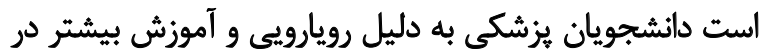

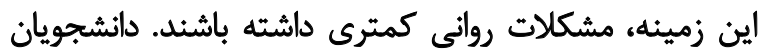

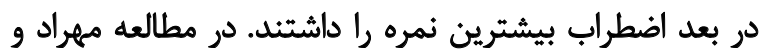

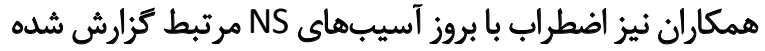

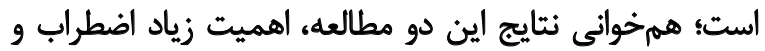

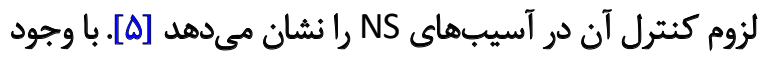

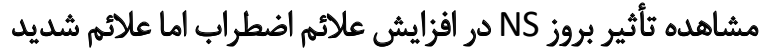

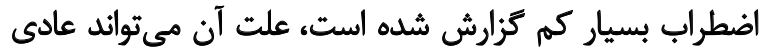

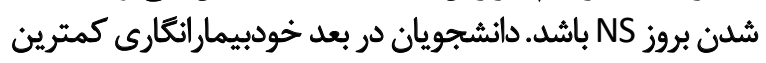

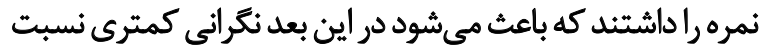
به ساير ابعاد وجود داشته باشد.

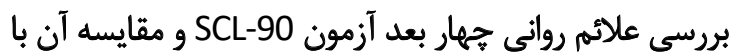

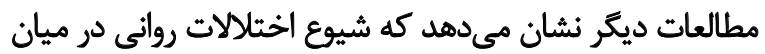

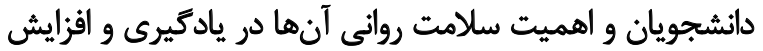

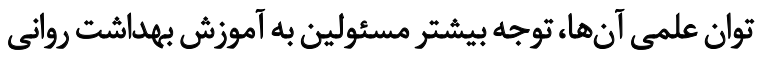

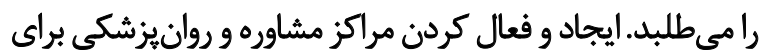

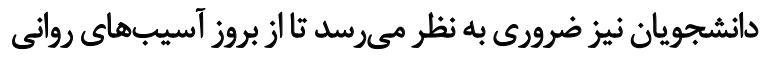
به خصوص يس از NS بيشكيرى به عمل آيد.

\section{نتيجلهيرى}

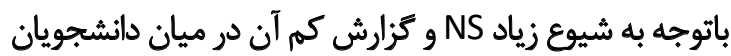

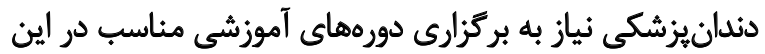

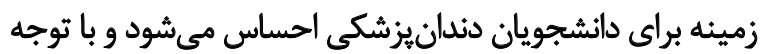

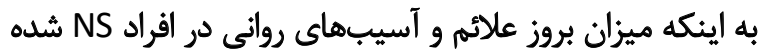

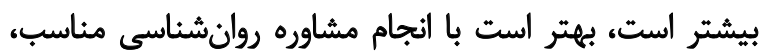

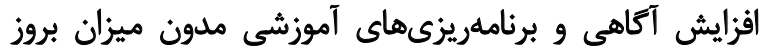
آسيبهاى روانى را به حداقل رساند.

با توجه به اهميت موضوع و مطالعات كم در اين زمينه در بين

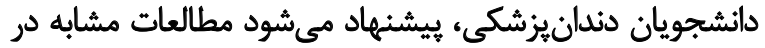

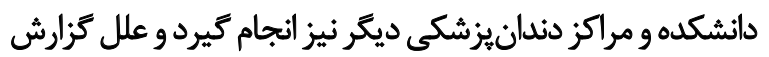




\section{References}

[1] Vose JG, McAdara-Berkowitz J. Reducing scalpel injuries in the operating room. Aorn J. 2009; 90(6):867-72.[DOI:10.1016/j.aorn.2009.07.025]

[2] Taghavi R, Tavakoli Tabasi K, Mohamadi S, Kor K. [Frequency of work injuries of needle stick among personnel in Sina Hospital in 2011 (Persian)]. J Neyshabur Univ Med Sci. 2015; 2(5):22-8. http://journal.nums. ac.ir/browse.php?a_id=83\&sid=1\&slc_lang=en

[3] Hashemipour M, Sadeghi A. Needlestick injuries among medical and dental students at the university of Kerman. A questionnaire study. Front Dent. 2008; 5(2):71-6. https://fid.tums.ac.ir/index.php/fid/article/view/150

[4] Mukram Ali F, Patil A, Prasant MC, Tahasildar S, Patil K. Needle stick injuries in dental clinics: A review. J Evol Med Dent Sci. 2014; 3(2):374-8. [DOI:10.14260/jemds/2014/1836]

[5] Mehrad R, Atkins EH, Sharifian SA, Pouryaghoub G. Psychosocial factors at work and blood-borne exposure among nurses. Int J Occup Environ Med. 2014; 5(1):32-9. [PMID][PMCID]

[6] Pervaiz M, Gilbert R, Ali N. The prevalence and underreporting of needlestick injuries among dental healthcare workers in Pakistan: A systematic review. Int J Dent. 2018; 2018:9609038. [DOI:10.1155/2018/9609038] [PMID] [PMCID]

[7] Abareshi F, Hekmatshoar R, Zokaei M, Akrami R. [Survey of occupational exposure to needle stick and its risk factors among Healthcare Workers in one of Sabzevar's hospital (Persian)]. Iran Occup Health. 2018; 14(6):70-7.http://ioh.iums.ac.ir/browse.php?a_id=1892\&sid=1\&slc_ lang=en

[8] Askarian M, Malekmakan L. The prevalence of needle stick injuries in medical, dental, nursing and midwifery students at the university teaching hospitals of Shiraz, Iran. Indian J Med Sci. 2006; 60(6):227-32.[PMID]

[9] Sepkowitz KA. Occupationally acquired infections in health care workers. Part II. Ann Intern Med. 1996; 125(11):917-28.[PMID]

[10] Santhosh K. Knowledge, attitude and practices regarding needlestick injuries among dental students. Asian J Pharm Clin Res. 2016; 9(4):312-5. https://innovareacademics.in/journals/index.php/ajpcr/ article/view/12230

[11] van der Laan L, van Spaendonck K, Horstink MWIM, Goris RJA. The symptom checklist-90 revised questionnaire: No psychological profiles in complex regional pain syndrome-dystonia. J Pain Symptom Manage. 1999; 17(5):357-62.[DOI:10.1016/S0885-3924(99)00009-3]

[12] Derogatis LR, Lipman RS, Covi L. SCL-90: An outpatient psychiatric rating scale-- Preliminary report. Psychopharmacol Bull. 1973; 9(1):13-28. [PMID]

[13] Sharhraky Vahed A, Mardani Hamuleh M, Asadi Bidmeshki E, Heidari M, Hamedi Shahraky S. [Assessment of the items of SCL90 test with quality of work life among Amiralmomenin Hospital personnel of Zabol City (Persian)]. Avicenna J Clin Med. 2011; 18(2):50-5. http://sjh.umsha. ac.ir/browse.php?a_id=238\&sid=1\&slc_lang=en

[14] Tabrizizadeh M, Yasini Ardakani SM, Rostamzade P, Zare M. [The mental health status of students of medicine and dentistry; A study in Shahid Sadoughi University of Medical Sciences, Yazd, Iran (Persian)]. Strides Dev Med Educ. 2012; 9(2):153-61. http://sdme.kmu.ac.ir/article_90239.html

[15] Melani PN. Harrison's principles of internal medicine. JAMA. 2012; 308(17):1813-4.[DOI:10.1001/jama.308.17.1813-b]
[16] Sharma L, Pradhan D, Todkar M, Sinha KP, Das M, Neha. Infection control and dentistry: A review. Int J Oral Health Med Res. 2018; 5(3):27-9. http://www.ijohmr.com/upload/Sharma\%20L\%20et\%20al(3).pdf

[17] Yang YH, Liou SH, Chen CJ, Yang CY, Wang CL, Chen CY, et al. The effectiveness of a training program on reducing needlestick injuries/sharp object injuries among soon graduate vocational nursing school students in southern Taiwan. J Occup Health. 2007; 49(5):424-9. [DOI:10.1539/ joh.49.424][PMID]

[18] Shah SM, Merchant AT, Dosman JA. Percutaneous injuries among dental professionals in Washington State. BMC Public Health. 2006; 6:269. [DOI:10.1186/1471-2458-6-269]

[19] Azami M, Hafezi Ahmadi MR, Sayehmiri K. Hepatitis B vaccination efficacy in Iranian healthcare workers: A meta-analysis study. Hepat Mon 2017; 17(1):e37781. [DOI:10.5812/hepatmon.37781] 


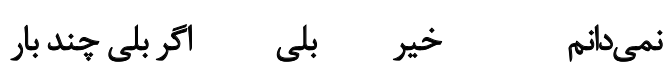

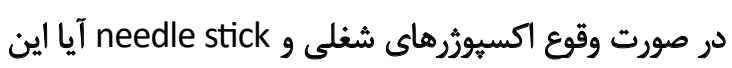
وضعيت به كسى اطلاع داده شده است؟ خير بلى بلى اكر اين وضعيت را كزارش ندادهايد علت جهه بوده است؟ - اطلاع نداشتن از مكانيسمهاى موجود در اين زمينه - نبود سيستم ثبت needle stick

در صورت وقوع اكسيوررهاى شغلى و needle stick آيا ميدانيد جه كارى بايد انجام دهيد؟ خير بلى بلى در صورت مثبت بودن سؤال قبل آنها را فقط نام ببريد. - در مورد needle stick به سؤالات زير ياسخ دهيد. زمان و شرايط وقوع needle stick

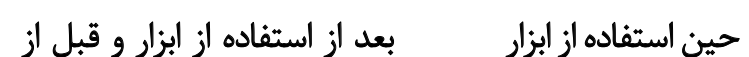

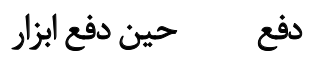

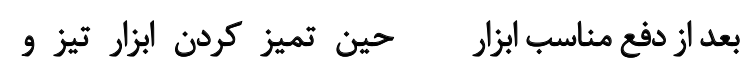
برنده بعد از دفع نامناسب ابزار ساير موارد needle stick وسيله استفادهشده در هنكام مورد سوزن كج لابراتوار

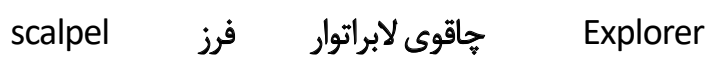
ساير نوع عمل در هنكام needle stick نسار recapping تميز كردن ابزار تعويض كاريول برداشتن سوزن از سرنك اعمال مرتبط بادفع ابزار تزريق بى حسى موضعى

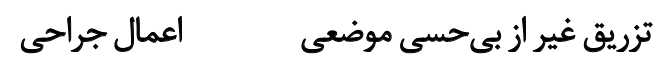

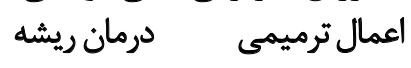
دندانيزشكى كودكان اعمال ارتودنسى ساير

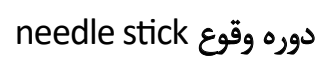

$$
\text { بالينى بره كلينيك }
$$

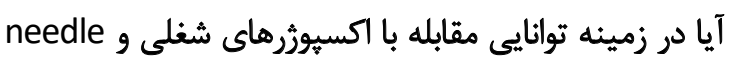
stick

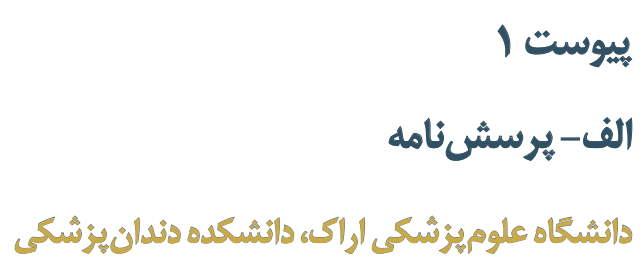

دانشجوى محترم يرسشنامه حاضر براى انجام پاياننامه

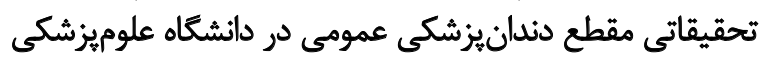

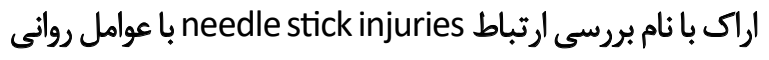

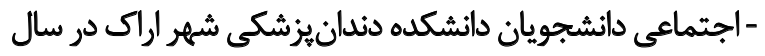

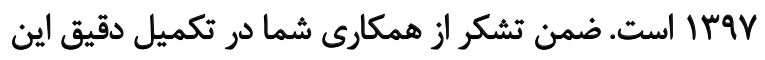

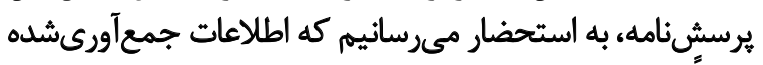

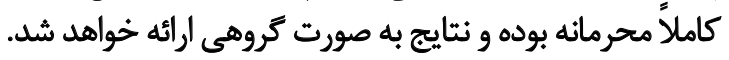

$$
\begin{aligned}
& \text { شماره يرسشنامه : }
\end{aligned}
$$

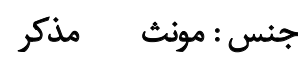

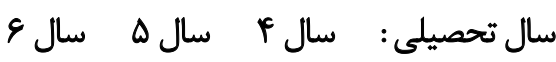

-آيا در طول دوران تحصيل يكى از موارد زير براى شما اتفاق ساق سأ سال

افتثاده است

فرو رفتن سوزن تزريق دندانيزشكى بعد از اتمام تزريق در بلن شما

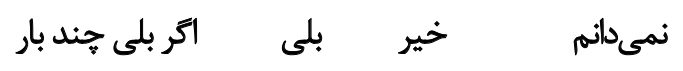
در صورت مثبت بودن سؤال قبل آيا نفوذ سوزن از روى برى برى بردي دستكش بوده است؟ مثبت بون

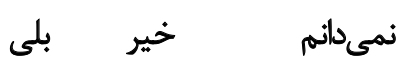
آيا خون يا بزاق بيمار حين كار به جشم شما وارد شده است؟ بـى

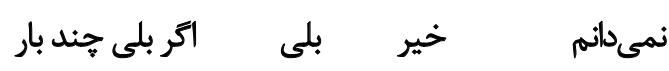

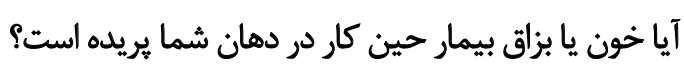

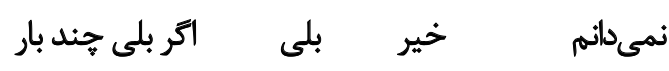
آيا تاكنون سوزن بخيه استفاده شده به دست شما وارد شده است ؟ - اسك

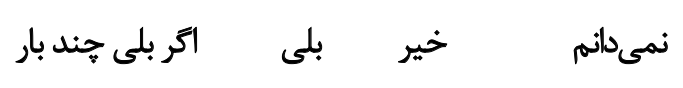

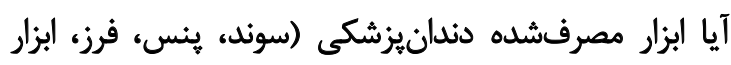

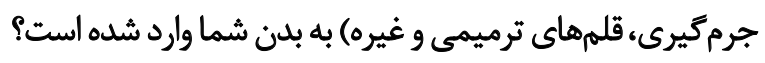

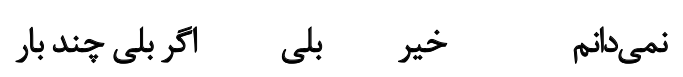
اكر بلى جه وسيلهاى آيا بدن شما با يكى از وسايلى كه برايلى بيمار استفاده شده

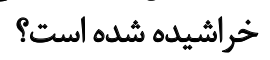




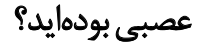

بههيجوجه كمى تاحدى زياد

دجار ضعف، بى حالى و يا سركيجه بودهايد؟

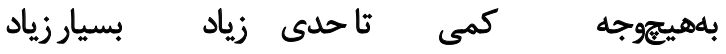

درد در ناحيه قلب يا سينه داشتهايد؟

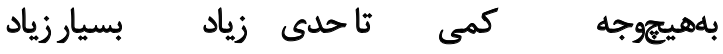

از رفتن به جاهاى باز يا خيابان احساس ترس كردهايد؟

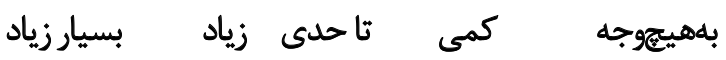

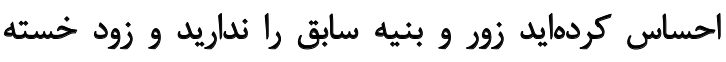

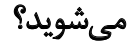

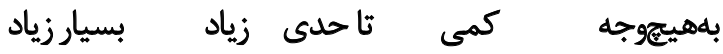

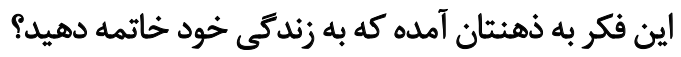

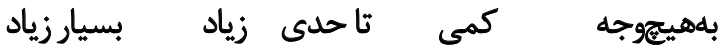

احساس لرزش در اندام بدن خود داشتهايد؟

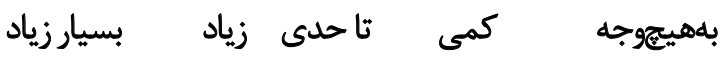
بىاشتهاشدهايد؟

بههيجوجه كمى تاحدى زياد

ناكهان و بدون دليل دجار ترس شديد شدهايد؟

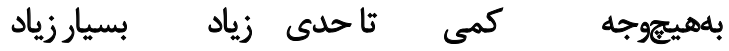

اين احساس را داشتهايد كه بترسيد تنها از خانه بيرون برويد؟

بهاهيجوجه بمى باحدى زيار زياد براي هر جيز كوجكى خود راسرزنش كردهايد؟

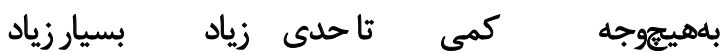
كمردرد داشتهايد؟

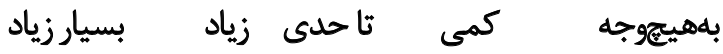
احساس تنهايى كردهايد؟

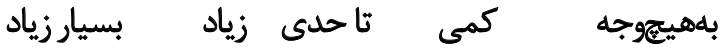
احساس غمكينى داشتهايد؟

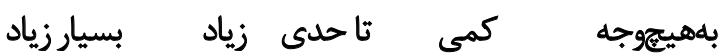
براى هر جيزى بلهدت نكَران و دلوايس شدهايد؟

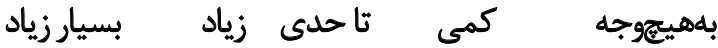

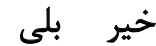

آيا آموزشهاى ارائهشده به شما توانايى مقابله با اكسيورثهاى

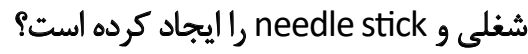
خير بلى تاحدودى آيا بر عليه هياتيت B واكسينه شدهايد؟ خير بلى جند دُز واكسن تزريق كردهايد؟ ا بيشتر ازئز آيا مي دانيد فواصل زمانى اين واكسنها جكونه است؟ (توضيح دهيد) آيا تست تيتر آنتىبادى انجام دادهايد؟

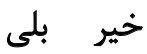

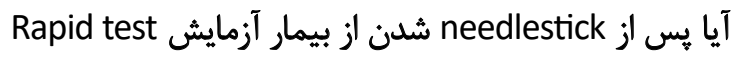

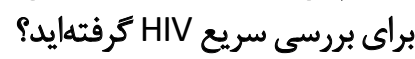
خير بلى آيا يس از needlestick شدن از بيمار آزمايش

HCV Ab

خير بلى آيا يس از HIV Ab HBS Ag شدن آزمايش

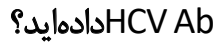
خير بلى

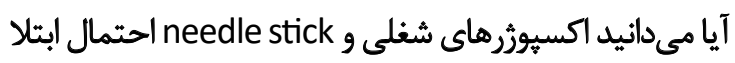
به جه بيمارى إيى ائي رايجاد مي كنئد؟ خير بلى -در صورت مثبت بودن سؤال قبل آنها را فقط نام ببريد. تعداد دُز واكسن مورد نياز جه تعداد است؟

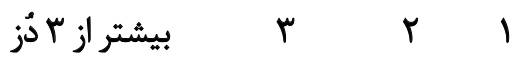

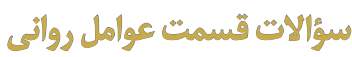

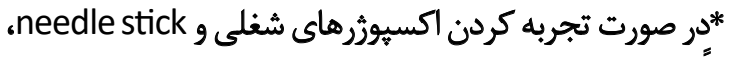

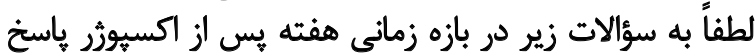
sol

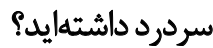
به هيجوجه بمى تاحدى زياد 


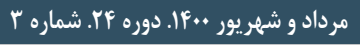

مجله دانشعًاه علوم يزّشكى الاكـ

از تنها ماندن ترس و واهمه داشتهايد؟

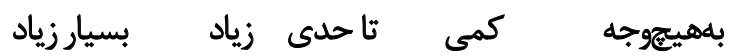

كاهي طورى بى قرار شدايد كه نتوانيد يك جا آرام بكيريد؟

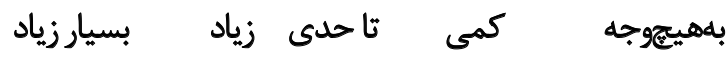

در بعضى از قسمتهاى بدن خود احساس ضعف و سستى

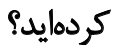

بهايجوجه

در دستها و ياها احساس سنغينى كردمايد؟ باء

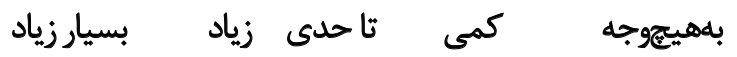

اين احساس را داشتهايد كه اتفاق بدى برايتان خواهد افتاد؟

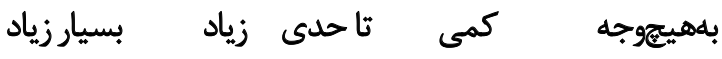

ترس از افتادن و از حال رفتن در انظار مردم را داشتهايد؟

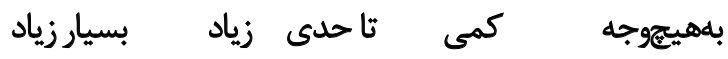

اعتقاد و تصورات ترسآميز داشتهايد؟

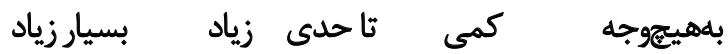

نسبت به هملجيز بي علاقه شدهايد؟

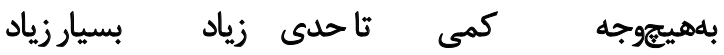

احساس ترس داشتهايد؟

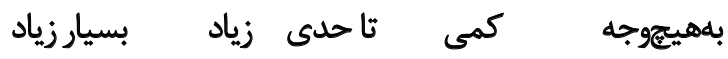

تيش قلب داشتهايد؟

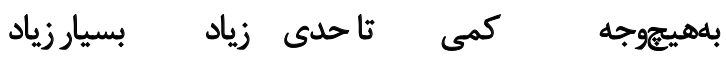

حالت تهوع يا دل بجهمخوردى داشتهايد؟

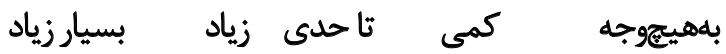

احساس درد و كوفتتى عضلات در بدنتان داشتهايد؟

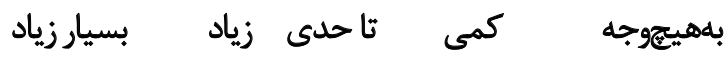

از مسافرت با اتوبوس يا قطار احساس ترس كردمايد؟

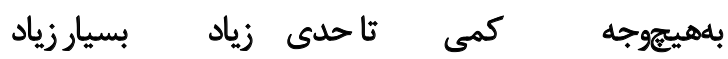

احساس تنتكى نفس داشتهايد؟

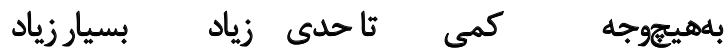

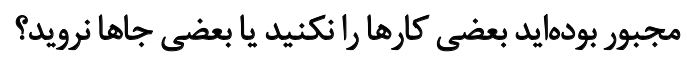

كمى تاحدى زياد بسيار زياد

بهايجوجه

احساس كردهايد بدنتان به خواب مىرود يا مورمور مىشود؟ بهى بهي

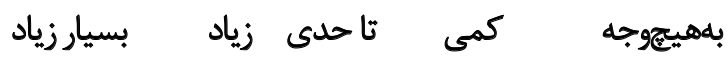

در كلويتان احساس كرفتئى كردهايد مثل اينكه جيزى در بردئ كلويتان كير كرده باشد؟ كانو كرفت

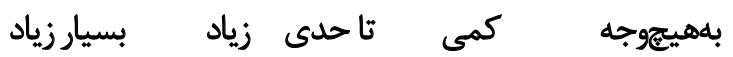

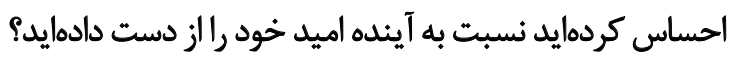
كمى تاحدى زياد بسيارزياد

دجار فشارهاى روحى بودهايد؟

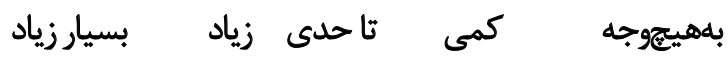
وقتى در جمع بودهايد احساس ناراحتى كردمايد؟ بهى

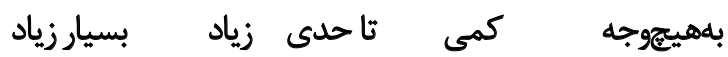

حتى كارهاى كوجى برايتان سخت بوده است؟

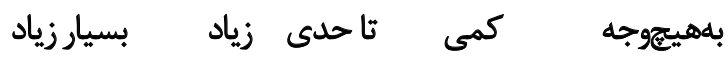

دجار هول و يا وحشتزدمى شدهايد؟

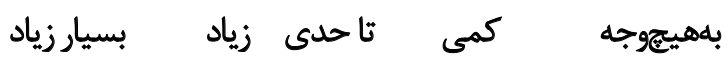

ill

محمد بخث آور و همكاران. جراحت ناشيى ازٔ سوزن و عوامل رواثى همراه با آن در ميان داتشجويان دثدانيزشكى 